\title{
Ambulatory blood pressure during once-daily randomised double-blind administration of atenolol, metoprolol, pindolol, and slow-release propranolol
}

\author{
J S FLORAS，J V JONES，M O HASSAN，P SLEIGHT
}

\begin{abstract}
Intra-arterial ambulatory blood pressure was measured over 24 hours, in 34 patients with newly diagnosed hypertension, both before and after double-blind randomisation to treatment with atenolol $(n=9)$, metoprolol $(\mathbf{n}=9)$, pindolol $(n=9)$, or propranolol in its slow-release form $(n=7)$. The dosage of each drug was adjusted at monthly clinic visits until satisfactory control of blood pressure was achieved (140/90 $\mathrm{mm}$ Hg or less by cuff) or the maximum dose in the study protocol was reached. A second intra-arterial recording was made after these drugs had been taken once daily at 0800 for three to eight months (mean 5.0 \pm SD 1.4) and was started four hours
\end{abstract} after the last dose.

At the end of the 24-hour recordings blood pressure was significantly lower with all four drugs. The extent to which the drugs reduced blood pressure, however, differed over the 24 hours. Atenolol lowered mean arterial pressure significantly throughout all 24 recorded hours, metoprolol for 12 hours, pindolol for 15 hours, and slowrelease propranolol for 22 hours. Neither metoprolol nor pindolol lowered blood pressure during sleep. A significant reduction in heart rate was observed over 20 hours with atenolol, 20 hours with metoprolol, 10 hours with pindolol, and 24 hours with slow-release propranolol. Atenolol, metoprolol, and slow-release propranolol continued to slow the heart rate 24 hours after the last tablet was taken; this effect on heart rate, however, was not sustained throughout the second morning in those patients taking atenolol. Pindolol, the only drug studied that has intrinsic sympathomimetic activity, increased heart rate and did not lower blood pressure during sleep.

Atenolol and slow-release propranolol are effective as antihypertensive agents over 24 hours when taken once daily, whereas metoprolol and pindolol may need to be taken more frequently. At times of low sympathetic tone, however, such as during sleep, beta-blockers with intrinsic sympathomimetic activity may raise heart rate and attenuate the fall in blood pressure with treatment.

\section{Introduction}

Compliance is often poor when patients are taking several antihypertensive drugs. ${ }^{1}$ Once-daily dosing with diuretics, ${ }^{2}$ methyldopa ${ }^{3}$ or beta-adrenoceptor-blocking drugs ${ }^{4}$ has therefore been advocated. The fairly short plasma elimination half life of many

Department of Cardiovascular Medicine, John Radcliffe Hospital, Oxford OX3 9DU

I S FLORAS, MD, DPHIL, research fellow (present address: Cardiology Department, Sunnybrook Medical Centre, University of Toronto, Canada M4N 3M5)

J V JONES, PHD, MRCP, clinical reader (present address : Cardiology Department, Bristol Royal Infirmary, Bristol BS2 8HW)

M O HASSAN, MD, PHD, research fellow (present address: Department of Physiology, Faculty of Medicine, King Abdul Aziz University Hospital, Jeddah, PO Box 9029, Saudi Arabia)

P SLEIGHT, MD, FRCP, Field-Marshal Alexander professor beta-blockers suggests, however, that they might not reduce blood pressure effectively for a full 24 hours. ${ }^{5-7}$ Most studies of once-daily beta-blockade have measured clinic blood pressure at rest or during exercise, or both. ${ }^{8-18}$ Atenolol, metoprolol, pindolol, and slow-release propranolol, among others, have been studied in this fashion.

Continuous ambulatory monitoring, which gives a direct, beat-to-beat measure of blood pressure, has advantages over clinic cuff records in assessing the extent and duration of effect of antihypertensive agents when subjects are at liberty to go about their normal daily activities. ${ }^{19}$ Earlier, we found that atenolol taken once daily for two to nine months effectively reduced ambulatory blood pressure for up to 28 hours after the last dose was administered. ${ }^{20}$ Other beta-blocking agents have been studied individually with this technique, ${ }^{41-24}$ but the results of these investigations have not always been in agreement. We, therefore, undertook a randomised, double-blind comparison of the effect of these four beta-adrenoceptor-blocking drugs, with their differing properties, formulations, and plasma half lives (when taken once daily), on ambulatory blood pressure and heart rate.

\section{Patients and methods}

\section{PROTOCOL}

Thirty-four asymptomatic patients (24 men and 10 women) of mean age 47 years (range 16-69 years) completed this study. They were referred to the hypertension clinic with newly diagnosed, untreated hypertension. Two of us measured the patients' recumbent blood pressure in the right arm, using a standard mercury sphygmomanometer (Accoson), after they had had 10 minutes of quiet rest. Phase V of the Korotkoff sounds described diastolic blood pressure. Blood pressure was measured in this fashion in the clinic on three or more occasions at least one week apart. Cuff blood pressures of 140/90 $\mathrm{mm} \mathrm{Hg}$ or greater in patients aged under 40 and of $160 / 95 \mathrm{~mm} \mathrm{Hg}$ or greater in patients aged 40 or older confirmed the presence of high blood pressure. Secondary causes of hypertension were excluded. The mean cuff pressures $( \pm S D)$ on the final clinic visit before entry into the study were $176 \pm 24 / 108 \pm 10 \mathrm{~mm} \mathrm{Hg}$. Almost all patients had clinic diastolic blood pressures greater than $95 \mathrm{~mm} \mathrm{Hg}$.

Ambulatory blood pressures and electrocardiograms were then recorded over 24 hours using direct ambulatory monitoring. This technique has been described in detail elsewhere. ${ }^{19} 202526$ Once fitted with the ambulatory monitoring apparatus, patients left the hospital between 1200 and 1300 and resumed their normal routine for 24 hours, returning to hospital for 15 minutes in the evening for maintenance of the perfusion unit. They were given a voice recorder and a digital watch and instructed to keep an accurate record of their activities, paying particular attention to the times of retiring and waking.

Patients were then randomised to one of four beta-adrenoceptorblocking agents, each to be taken once daily in the morning. The initial dose of these drugs was: atenolol $100 \mathrm{mg}(\mathrm{n}=9)$, metoprolol $200 \mathrm{mg}$ $(n=9)$, pindolol $15 \mathrm{mg}(n=9)$, and slow-release propranolol $160 \mathrm{mg}$ $(n=7)$. The randomisation schedule was held in the hospital pharmacy, and the manufacturers provided us with white, unmarked formulations. Neither we nor the patients were aware of the assigned drug.

The patients were reviewed at the same time of day at monthly intervals in the hypertension clinic. They were asked to continue taking their medication on the morning of these visits. If a cuff blood pressure of $140 / 90 \mathrm{~mm} \mathrm{Hg}$ or less was not achieved the dose was increased as follows: atenolol to $200 \mathrm{mg}$ but no further; metoprolol 
to $300 \mathrm{mg}$, then $400 \mathrm{mg}$; pindolol to $30 \mathrm{mg}$, then $45 \mathrm{mg}$; and slowrelease propranolol to $320 \mathrm{mg}$, then $480 \mathrm{mg}$, then $640 \mathrm{mg}$, all to be taken once daily. Doses were not increased beyond these levels even if the blood pressure did not fall below $140 / 90 \mathrm{~mm} \mathrm{Hg}$ after four months of treatment at the highest level.

After three to eight months (mean $5 \cdot 0 \pm 1 \cdot 4$ ) of once-daily administration we obtained a second 24-hour record of ambulatory blood pressure. The final tablets were taken at around 0800 . As on the first occasion, the ambulatory intra-arterial recordings began between 1200 and 1300. Thus these 24-hour records were obtained over a period five to 28 hours after the last oral dose was taken. The arterial cannulas were removed at the end of this 24 hours. Patients were asked to adhere to a routine similar to that during the first study.

The nature of the procedure was explained to each participant and informed, written consent obtained on both occasions. The protocol was approved by the hospital ethics committee.

Two of the patients took additional drugs during the study: one (who received atenolol) took digoxin to control paroxysmal atrial fibrillation, and the other (slow-release propranolol) took salazopyrin (sulphasalazine) for Crohn's disease. The dose of these drugs was not altered during these investigations.

\section{ANALYSIS OF THE AMBULATORY RECORD}

The completed 24-hour record was replayed from the cassette at 25 times real time (Oxford Instruments Replay Unit) and analysed by computer (Data General Eclipse S-200). ${ }^{27}$ Raw data were displayed on an oscilloscope and any periods of the record marred by damping of the pressure wave or recording artefacts edited. The computer calculated systolic, mean, and diastolic blood pressures and pulse interval and stored this information for each heart beat. The percentage of the data edited from the record was also noted. Data from the "clean" periods of the record were compressed into hourly frequency histograms. Frequency histograms of blood pressure and pulse interval were also calculated for the waking and sleeping periods, as defined by the patients' diaries; waking was further subdivided into days 1 and 2 and frequency histograms constructed for each day. Hourly mean values and mean values from the histograms for the longer periods were used to examine the effect each drug had on blood pressure and pulse interval.

Pulse interval (that is, the interval between cardiac cycles) rather than its inverse, heart rate, was retained for subsequent calculations $c$ and parametric statistical analyses (Student's $t$ test), since the distri- $\overline{\widehat{O}}$ bution of pulse intervals about the hourly or daily mean value tended to be normal in these frequency histograms whereas the distribution of heart rates tended to be skewed. Since the inverse relation between $\mathbb{D}$ pulse interval and heart rate is hyperbolic rather than linear, pulse interval was not converted to heart rate until after these calculations had been completed; for convenience these data are expressed in terms of heart rate for presentation in table II.

\section{STATISTICAL METHODS}

Only those frequency histograms of blood pressure and pulse interval free of editing in both the control (untreated) and the treated on ambulatory records were paired for statistical analysis. The acceptable risk of making a type 1 (alpha) error was set at 0.05 . As our sole intention was to examine the extent to which the drugs lowered blood pressure and heart rate (that is, conclusions we would draw from finding a rise in blood pressure (or heart rate) would be equivalent to those we would draw from finding no change in blood pressure (or heart rate) while the drug was being taken) we used one-tailed tests $N$ of significance (Student's $t$ test, paired) for the comparisons of pretreatment and posttreatment values. All other statistical comparisons used two-tailed tests of significance.

Analysis of the ambulatory records was performed in the following sequence. To test the hypothesis that each of the drugs produced a significant lowering of the waking ambulatory blood pressure (and increase in pulse interval) the mean values for the entire periods over $\mathrm{O}$ which these patients were awake, before and after treatment, were compared (paired $t$ test). The entire 24-hour ambulatory record was then divided into the two waking periods-that is, the first day and the $Z$ second morning of the study-and the one sleeping period, and the mean blood pressures and pulse intervals during these periods before and after treatment were also compared (paired $t$ test). We wished to determine whether the fall in blood pressure (and the increase in pulse

TABLE I-Mean $\pm S D$ age, sex, clinic blood pressures before first (untreated) and second (treated) 24-hour ambulatory recordings, dose of each drug (taken once daily), and duration of beta-blockade before second study

\begin{tabular}{|c|c|c|c|c|c|c|c|c|}
\hline \multirow{2}{*}{ Drug } & \multirow{2}{*}{$\begin{array}{c}\text { No } \\
\text { of } \\
\text { patients }\end{array}$} & \multirow{2}{*}{$M: F$} & \multirow{2}{*}{$\begin{array}{c}\text { Age } \\
\text { (years) }\end{array}$} & \multicolumn{2}{|c|}{ Mean clinic blood pressure $(\mathrm{mm} \mathrm{Hg}$ ) before: } & \multirow{2}{*}{$\mathrm{p}^{*}$} & \multirow{2}{*}{$\begin{array}{l}\text { Dose during } \\
\text { second } \\
\text { study (mg) }\end{array}$} & \multirow{2}{*}{$\begin{array}{c}\text { Duration of } \\
\text { beta-blockade } \\
\text { (months) }\end{array}$} \\
\hline & & & & First study & Second study & & & \\
\hline $\begin{array}{l}\text { Atenolol } \\
\text { Metoprolol } \\
\text { Pindolol } \\
\text { Slow-release propranolol }\end{array}$ & $\begin{array}{l}9 \\
9 \\
9 \\
7\end{array}$ & $\begin{array}{l}7: 2 \\
7: 2 \\
7: 2 \\
3: 4\end{array}$ & $\begin{array}{l}48 \cdot 2 \pm 10 \cdot 8 \\
44 \cdot 8 \pm 14 \cdot 4 \\
50 \cdot 7 \pm 14 \cdot 0 \\
45 \cdot 1 \pm 9 \cdot 4\end{array}$ & $\begin{array}{l}173 \pm 26 / 107 \pm 9 \\
169 \pm 20 / 102 \pm 4 \\
179 \pm 26 / 111 \pm 10 \\
183 \pm 25 / 112 \pm 15\end{array}$ & $\begin{array}{l}143 \pm 32 / 90 \pm 20 \\
160 \pm 25 / 96 \pm 14 \\
150 \pm 27 / 98 \pm 13 \\
152 \pm 25 / 96 \pm 15\end{array}$ & $\begin{array}{l}0.01 / 0.05 \\
N S / 0.05 \\
0.01 / 0.05 \\
0.05 / 0.05\end{array}$ & $\begin{array}{l}128 \pm 56 \\
311 \pm 105 \\
33 \pm 10 \\
457 \pm 194\end{array}$ & $\begin{array}{l}4 \cdot 8 \pm 1 \cdot 4 \\
5 \cdot 0 \pm 1 \cdot 3 \\
5 \cdot 3 \pm 1 \cdot 5 \\
5 \cdot 1 \pm 1 \cdot 5\end{array}$ \\
\hline
\end{tabular}

Ages and initial blood pressures in each group did not differ significantly (unpaired Student's $t$ test, two tailed, adjusted for multiple comparisons).

Comparison of clinic blood pressures (systolic/diastolic) (paired Student's $t$ test, one tailed).

TABLE II-Effect of long-term once-daily beta-adrenoceptor blockade on waking and sleeping blood pressures and heart rates (means $\pm S D$ )

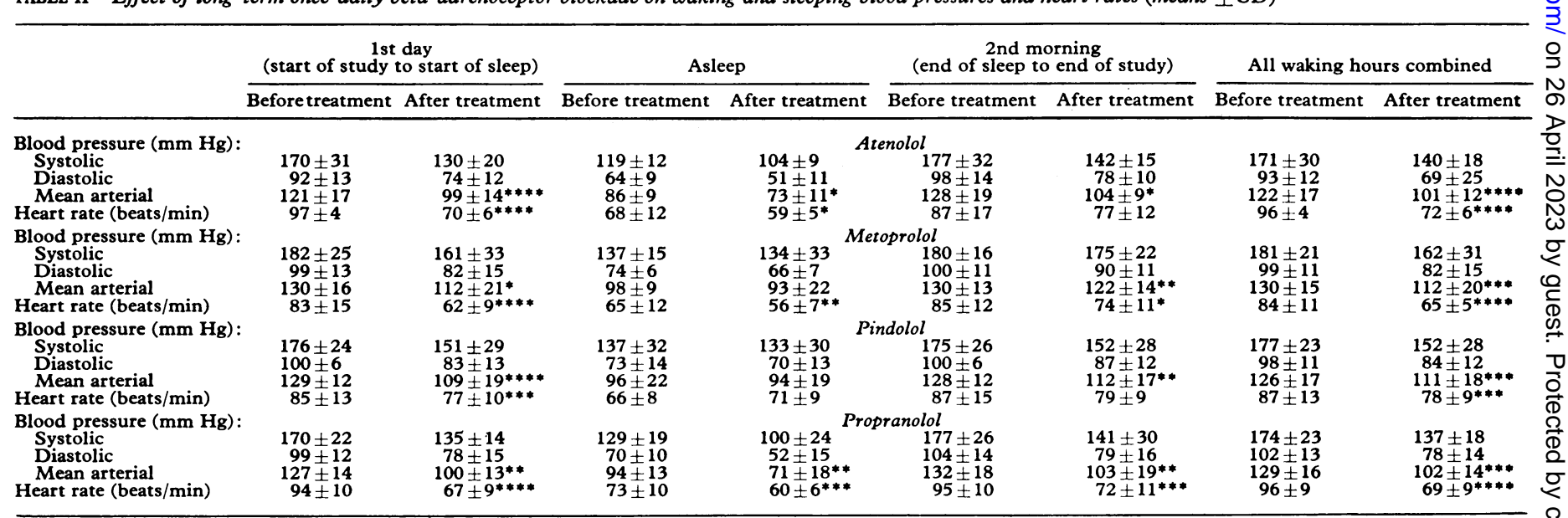

$* \mathrm{p}<0.05, * * \mathrm{p}<0.02, * * * \mathrm{p}<0.01, * * * * \mathrm{p}<0.001$ adjusted for multiple comparisons (Student's paired $t$ test (one tailed)). Increase in heart rate with pindolol during sleep significant $(p<0.01)$ using two-tailed paired $t$ test. 
interval) during each of these three periods was significant with each drug. As this entailed three comparisons of blood pressure (and pulse interval) in the same patient over time the $p$ value derived from these data was adjusted for multiple comparisons using the formula adjusted $p=1-(1-p) .^{328}$ The adjusted $p$ value appears in table II.

Having assessed the significance of the fall in blood pressure with each drug over each period, we wished to determine whether the extent to which blood pressure fell was equal on the first day, at night, and on the second morning of the study. This was tested by using analysis of variance for correlated groups ${ }^{29}$ to compare the fall in blood pressure with each beta-blocker during each of these three periods.

Finally, to study the effect of each drug on blood pressure and pulse
All four beta-blockers lowered systolic and diastolic blood pressures while patients were awake (table II); this effect could also be seen when the waking period of the first day was isolated. Atenolol and slowrelease propranolol lowered blood pressure significantly during sleep; metoprolol and pindolol did not. Again, on the second morning, 24 hours after the last dose was taken, mean arterial pressure was significantly reduced with all four drugs. In the case of metoprolol this was due to a drop in diastolic blood pressure, as systolic blood pressure was essentially unchanged.

The extent to which mean arterial pressure fell with treatment was similar during sleep and the two periods of wakefulness in those patients taking atenolol and slow-release propranolol but not in those

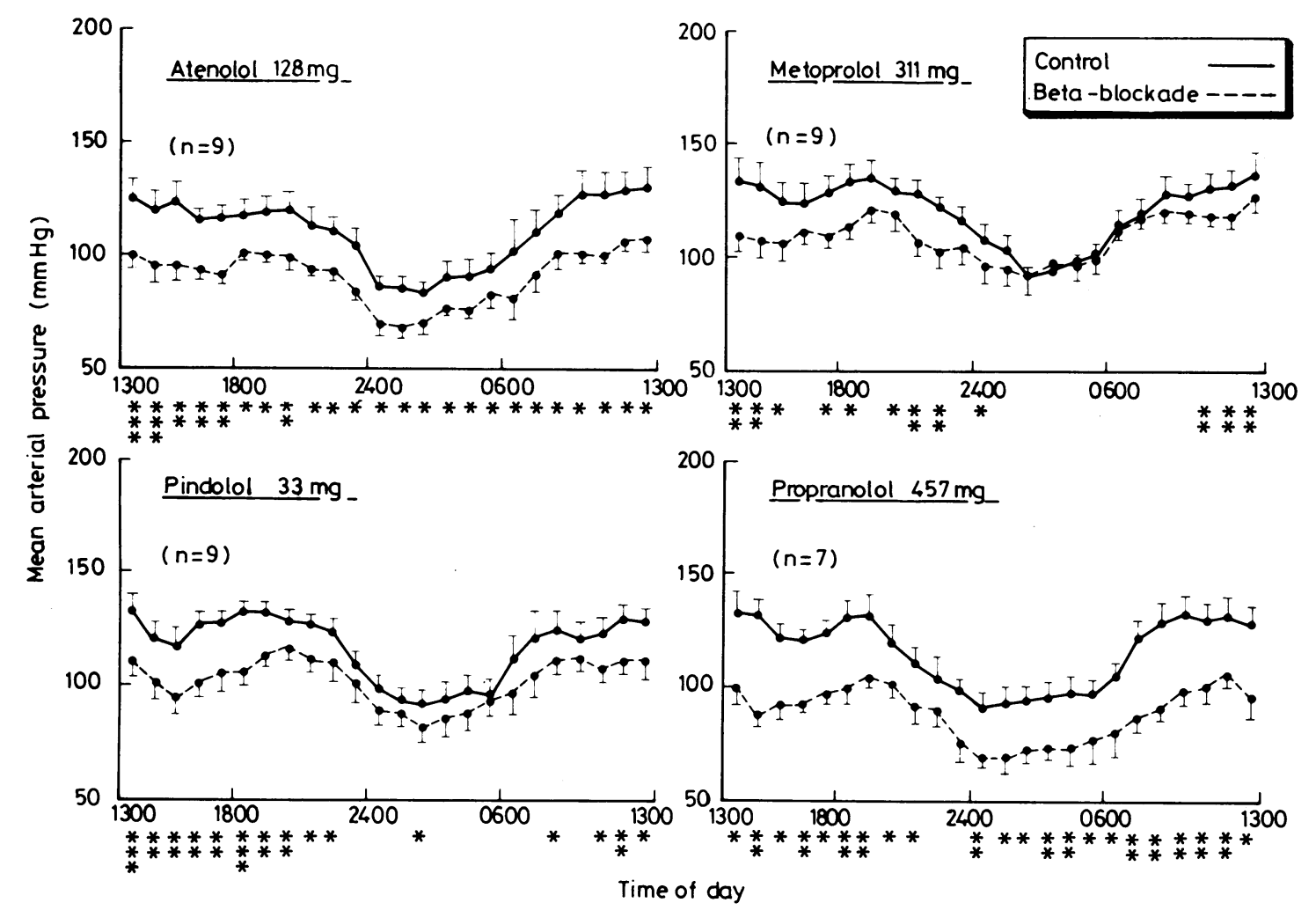

FIG 1-Mean \pm SE mean arterial pressure during each of the 24 hours of the records, before and after beta-adrenoceptor blockade with one of atenolol, metoprolol, pindolol, and slow-release propranolol.

Comparison of each pair of hourly means: ${ }^{*} \mathrm{p}<0.05,{ }^{* *} \mathrm{p}<0.01,{ }^{* * *} \mathrm{p}<0.001$ (one-tailed $t$ test).

interval over smaller periods of time the paired $t$ test was used to compare mean blood pressure and pulse intervals during each of the 24 hours recorded before and after treatment.

\section{Results}

The patients randomised to each group were similar in age and had similar clinic and ambulatory blood pressures before treatment (see tables I and II). Ambulatory heart rates when patients were awake tended to be higher in those assigned to take atenolol or metoprolol, but this was not significant when the $p$ value was adjusted for multiple comparisons.

The dose of beta-blocker remained unchanged in 11 of the patients, was increased in 22 (atenolol, three; metoprolol, five; pindolol, eight; and propranolol, six), and was halved in one, who felt fatigued when taking $100 \mathrm{mg}$ atenolol. Table I shows the mean daily dose of each drug and the length of time for which patients took the drug between the first and second studies.

EFFECT OF LONG-TERM ONCE-DAILY BETA-ADRENOCEPTOR BLOCKADE ON AMBULATORY BLOOD PRESSURES

In most patients a satisfactory, unedited record was obtained for the full 24-hour period, from 1300 on the first day to 1300 on the secondthat is, up to 28 hours after the last dose of drug. taking metoprolol or pindolol, in whom the fall during sleep was significantly less than the fall in the waking periods $(p<0 \cdot 01)$.

Figure 1 shows hour by hour comparisons of mean arterial pressure before and after treatment. More than 24 hours after the last dose mean arterial pressure was significantly lower with all four drugs, but their effects over the 24 hours differed. Atenolol lowered the pressure for all 24 hours, metoprolol for 12 hours, pindolol for 15 hours and slowrelease propranolol for 22 hours.

EFFECT OF LONG-TERM ONCE-DAILY BETA-ADRENOCEPTOR BLOCKADE ON HEART RATE

Falls in heart rate did not necessarily parallel falls in blood pressure, as can be seen by comparing figures 1 and 2 . Atenolol lowered the heart rate for 20 hours, metoprolol for 20 hours, pindolol for 10 hours, and slow-release propranolol for 24 hours (fig 2). All four beta-blockers reduced heart rate significantly when patients were awake (days 1 and 2 combined) (table II), and in particular throughout the waking period of day 1 . Atenolol, metoprolol, and slow-release propranolol continued to slow the heart rate 24 hours after the last oral dose was taken (fig 2); however, the reduction in the heart rate with atenolol and pindolol overall was not significant on the second morning of the study (table II). Atenolol, metoprolol, and slow-release propranolol, but not pindolol, lowered heart rate during sleep.

Pulse intervals tended to be shorter during sleep in the patients taking pindolol. As one-tailed tests of significance were used to 
analyse these data, however, this observation was equivalent to our finding no reduction in heart rate with this drug during sleep. We had not anticipated this in the original study design. Pulse intervals before and after treatment with pindolol were therefore restudied, using a twotailed $t$ test for comparison. This showed the increase in heart rate with pindolol during sleep to be significant $(p<0.01)$ (table II).

\section{SIDE EFFECTS}

Side effects were mild and no patient had to stop treatment. There was no obvious difference in incidence between any of the drugs. blood pressure significantly for five out of 24 hours and diastolic for seven hours in seven patients studied on the second occasion after two months of treatment. Again, these reductions were restricted to the waking period of the first day; blood pressure throughout the remainder of the record was lower but not significantly so. Several factors may have contributed to these divergent findings, including differences in the duration of treatment, the methods of data analysis, or the presence of one or two people who did not respond to beta-blockade, given the small numbers of patients studied.

The invasive nature of ambulatory monitoring does not lend

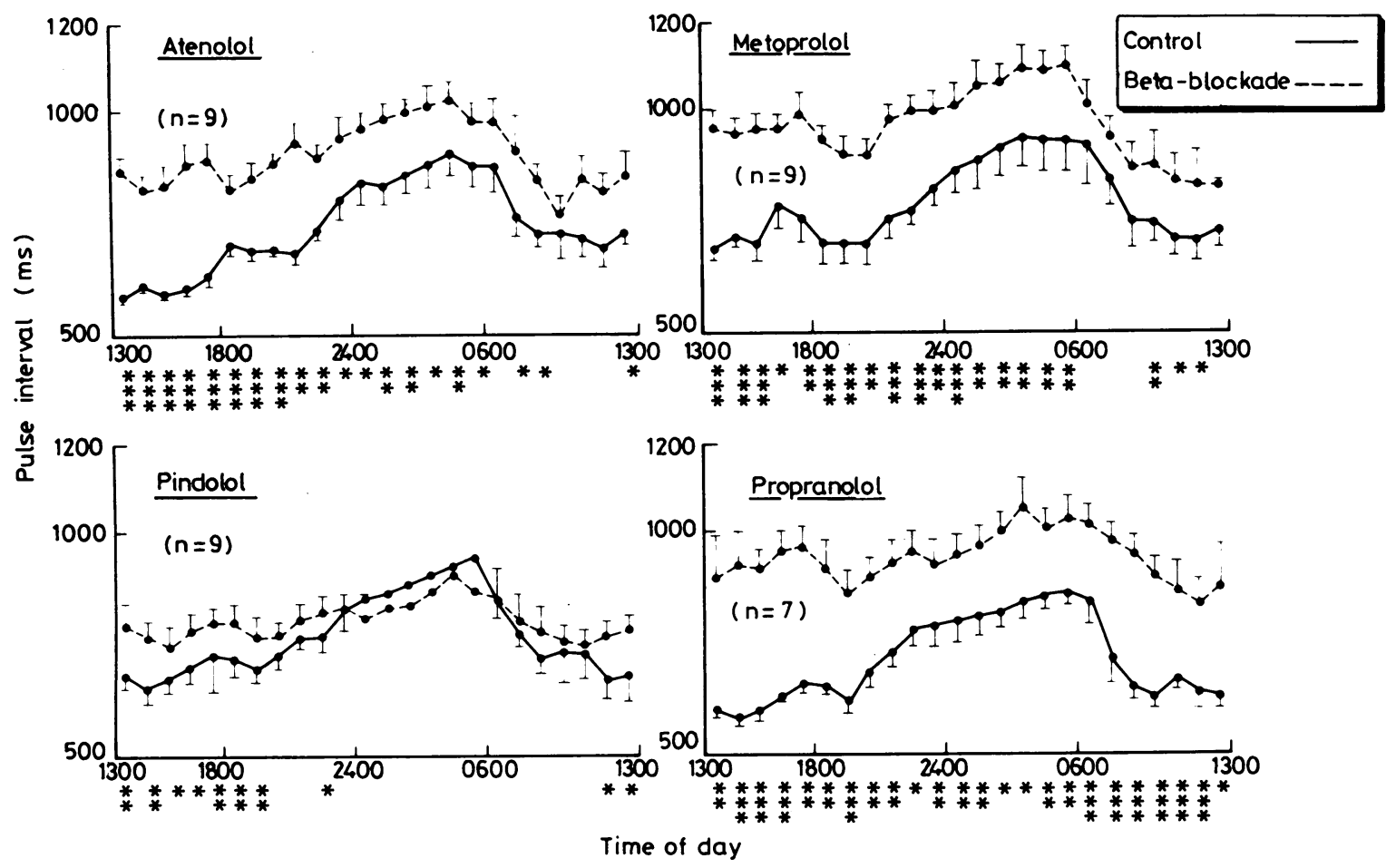

FIG 2-Mean + SE pulse intervals during each of the 24 hours of the records, before and after beta-adrenoceptor blockade with one of atenolol, metoprolol, pindolol, and slow-release propranolol. Longer pulse intervals are equivalent to slower heart rates.

Comparison of each pair of hourly means: ${ }^{*} \mathrm{p}<0.05,{ }^{* *} \mathrm{p}<0.01$ (one-tailed $t$ test).

\section{Discussion}

Although several workers have advocated once-daily betaadrenoceptor blockade in the treatment of high blood pressure, this study, using continuous intra-arterial ambulatory monitoring, shows that not all beta-blocking agents reduce blood pressure to a similar extent over 24 hours. In addition, we found that pindolol, a drug with high intrinsic sympathomimetic or partial agonist activity, may actually increase heart rate at night while not decreasing blood pressure.

Several beta-adrenoceptor-blocking agents have been studied with ambulatory monitoring, but the effectiveness of each, taken once daily, in lowering blood pressure over the full 24 hours has been argued. We found that atenolol, taken once daily for two to nine months, effectively reduced ambulatory blood pressure for up to 28 hours after the last dose was administered. ${ }^{20}$ Watson et $a l^{4}$ reported that propranolol, metoprolol, and acebutolol achieved a significant reduction of blood pressure over 24 hours when taken once daily, but patients were not randomised in a double-blind fashion to these drugs and the effect of each drug was not examined separately. Mehta et al, ${ }^{24}$ on the other hand, found that once-daily acebutolol reduced blood pressure on the first day of treatment but not at night or on the second morning of their recording. Mann et al ${ }^{23}$ reported that slow-release propranolol taken once daily reduced systolic the technique readily to cross-over study designs. To minimise the inconvenience and potential risk of complications we decided at the outset to limit the number of arterial cannulations to two per patient and to study a larger number of patients, randomised to one of the four drugs. The four groups thus obtained were similar in terms of age, initial clinic blood pressures, initial ambulatory blood pressures, and duration of treatment. Moreover, although the number of patients assigned to each drug was reduced by this protocol, the numbers studied were com- $N$ parable with those in earlier studies and sufficient to detect a $D$ significant clinical response if one arose. As may be seen in table II, in most instances statistically significant reductions accom- N panied clinically important reductions in blood pressure and $N$ heart rate; absence of statistical significance tended to occur when changes in these variables were of little clinical importance and were therefore unlikely to be due entirely to the number of subjects studied.

We did not think that a placebo period, entailing an additional arterial puncture, was a necessary adjunct to our study. Our own experience, as well as that of others, shows ambulatory $\mathbb{\mathbb { D }}$ intra-arterial records to be highly reproducible and insensitive to the ingestion of an inert tablet, obviating the need for a

In this study all four beta-blockers achieved a significant 8 reduction in mean arterial pressure 28 hours after the last single 
daily dose was taken. Had blood pressure been studied only at this time (by cuff) no difference between these four drugs would have emerged. Over the 24 hours under study (five to 28 hours after the last dose), however, the extent to which each of these drugs lowered blood pressure differed, with atenolol lowering mean arterial pressures for all 24 hours, metoprolol for 12, pindolol for 15, and slow-release propranolol for 22 . In contrast, twice-daily dosing with metoprolol would appear to lower blood pressure effectively throughout the 24 hours after the last dose. ${ }^{22}$

The fall in mean arterial pressure with treatment on the first and second waking days was similar with all four beta-blockers. The principal difference between these drugs arose during sleep, when atenolol and slow-release propranolol lowered mean arterial pressure but metoprolol and pindolol did not. Admittedly, the advantage of lowering blood pressure during sleep is not yet established, although it might be surmised that any lowering of blood pressure, whether by day or by night, might confer additional benefit to a patient with hypertension.

Atenolol, metoprolol, and slow-release propranolol continued to reduce heart rate 24 hours after the last dose was taken. Slow-release propranolol, which has an elimination half life of 20 hours, ${ }^{6}$ had the greatest effect on pulse interval in this study. The effect of metoprolol (elimination half life of four to five hours $^{2}$ ) on heart rate appeared to persist beyond that of atenolol (elimination half life seven to nine hours ${ }^{7}$ ), possibly reflecting the relatively higher doses of metoprolol (311 mg $v 128 \mathrm{mg}$ ) taken by the patients, although Erikssen $e t a^{32}$ found atenolol $100 \mathrm{mg}$ to be adequate but metoprolol $300 \mathrm{mg}$ to be insufficient in controlling exercise tachycardia 24 hours after a single dose. Reybrouck et al ${ }^{16}$ pointed out that if the indication for using metoprolol was simply to lower blood pressure then $300 \mathrm{mg}$ daily was equivalent when taken over the long term to $100 \mathrm{mg}$ thrice daily. The once-daily regimen, however, did not reduce exerciseinduced tachycardia to the same extent as the thrice-daily regimen in the hours preceding the subsequent dose.

The effectiveness of beta-adrenoceptor-blocking drugs in reducing blood pressure or exercise-induced tachycardia is not necessarily related to their plasma concentration. ${ }^{33}{ }^{34}$ Erikssen et $a^{32}$ found that $50 \%$ of the maximum reduction of exercise tachycardia remained 24 hours after a single oral dose of pindolol $(15 \mathrm{mg})$, which has an elimination half life of about five hours, ${ }^{5}$ although most of their subjects lacked detectable blood concentrations of the drug at this time. Moreover, after long-term administration is stopped up to three weeks of placebo "washout" may be required before blood pressure returns to pretreatment values. ${ }^{33}$ The reasons for this persistent beta-adrenergic blockade, more evident when the sympathetic nervous system is activated-for example, by exercise-than during rest or sleep, are not clear, but several explanations, including a residual effect of these drugs at the beta-receptor site or cellular adaptations secondary to beta-adrenoceptor blockade, have been advanced. $^{34}{ }^{33}$ This phenomenon may help to explain the reappearance of the hypotensive and bradycardiac effect of metoprolol and pindolol on the second morning of the study, when most subjects were active either at work or at home, after a hiatus during sleep.

Pindolol, alone of the four drugs, has intrinsic sympathomimetic activity. The presence of this became evident during sleep, when sympathetic tone is normally least, as an increase in heart rate above the control value. This effect has not been commented on previously; it would appear, however, that neither acebutolol taken once daily ${ }^{24}$ nor oxprenolol taken thrice daily ${ }^{21}$ (both of which possess intrinsic sympathomimetic activity but to a lesser degree than pindolol) lower heart rate or blood pressure during sleep. The authors of these particular studies suggested that the effect of beta-adrenoceptor blockade may be minimal during sleep but did not consider the alternative possibility that the partial agonist activity of these three drugs may prevent heart rate and blood pressure from falling below untreated values during periods of naturally decreased sympathetic tone.

A significant lowering of mean arterial pressure was observed with all four drugs 24 hours or more after ingestion of the last tablet in this study. However, the pattern of blood pressure reduction differed with each drug. We suggest, therefore, that not all beta-adrenoceptor-blocking drugs are equally effective as antihypertensive agents over 24 hours when taken once daily. Metoprolol may need to be taken more frequently or in its slowrelease form to achieve a significant reduction in blood pressure over 24 hours. Pindolol lowered mean arterial pressure significantly throughout most waking hours, but its sympathomimetic properties may prevent it from lowering blood pressure significantly during sleep, even with more frequent dosing. Atenolol,

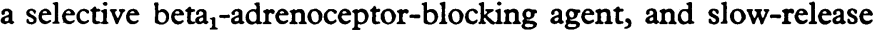
propranolol, which is non-selective, appear to be effective in mild to moderate hypertension when taken once daily over the long term.

This study was supported by grants from the Rhodes Trust, the British Heart Foundation, the Medical Research Council, Astra Pharmaceuticals, Imperial Chemical Industries, Sandoz, and Stuart Pharmaceuticals. We are grateful to Dr D Lee and Dr B Winsley, hospital pharmacists, who administered the drug treatment.

\section{References}

1 Blackwell B. The drug defaulter. Clin Pharmacol Ther 1972;13:841-8.

2 Wilcox RG. Randomised study of six beta-blockers and a thiazide diuretic in essential hypertension. Br Med $\mathcal{F} 1978$;ii:383-5.

${ }^{3}$ Wright JM, McLeod PJ, McCullough W. Antihypertensive efficacy of a single bedtime dose of methyl dopa. Clin Pharmacol Ther 1976;20:733-7.

4 Watson RDS, Stallard TJ, Littler WA. Influence of once-daily administration of $\beta$-adrenoceptor antagonists on arterial pressure and its variability. Lancet $1979 ; \mathrm{i}: 1210-3$.

${ }^{5}$ Gugler R, Bodem G. Single and multiple dose pharmacokinetics of pindolol. Eur $\mathcal{f}$ Clin Pharmacol 1978;13:13-6.

6 Shand DG, Wood AJ. Propranolol withdrawal syndrome-why ? Circulation 1978;58:202-3.

7 Harron DWG, Balnave K, Kinney CD, Wilson R, Russel CJ, Shanks RG. Effects on exercise tachycardia during 48 hours of a series of doses of atenolol, sotalol and metoprolol. Clin Pharmacol Ther 1981 ;29:295-302.

8 Wilson M, Morgan G, Morgan T. The effect on blood pressure of betaadrenoceptor blocking drugs administered once daily and their duration of action when therapy is ceased. Br $\mathcal{F}$ Clin Pharmacol 1976;3:857-61.

${ }^{9}$ Douglas-Jones AP, Cruickshank JM. Once daily dosing with atenolol in patients with mild or moderate hypertension. $\mathrm{Br} M e d \mathcal{F} 1976$;i: 990-1.

10 Jeffers TA, Webster J, Petrie JC, Barker NP. Atenolol once daily in hypertension. Br 7 Clin Pharmacol 1977;4:523-7.

11 Marshall AJ, Barritt DW, Harry JD. Dose response and frequency of administration of atenolol in essential hypertension-once daily treatment with beta-blockade. Postgrad Med $\mathcal{F}$ 1977;53, suppl 3:168-72.

12 Taub YM, Rosenfeld JB. Once a day pindolol in hypertension. Clin Pharmacol Ther 1977;21:588-92.

13 Castleden CM, Duthan JRE, George CF. A comparison of once and twice daily atenolol in hypertension. Postgrad Med $\mathcal{F} 1977 ; 53: 679-82$.

14 Frithz G. Pindolol once daily in the treatment of hypertension. Ups $\mathcal{F}$ Med Sci $1976 ; 81: 151-4$.

15 Douglas-Jones AP, Baber NS, Lee A. Once daily propranolol in the treatment of mild to moderate hypertension. Eur $\mathcal{F}$ Clin Pharmacol 1978;14: 163-6.

${ }^{16}$ Reybrouck T, Amery A, Fagard R, Jousten P, Ligmen P, Meulpas E Beta-blockers: once or three times a day ? $\mathrm{Br}$ Med 7 1978;i:1386-8.

17 Karlberg BE, Nilsson O, Tolagen K, Nitelius E, Waern U. Once daily treatment with metoprolol in primary hypertension. Effects on blood pressure in relation to plasma renin activity, urinary adosterone excretion and the concentration of metoprolol in plasma. Clin Pharmacol Ther $1979 ; 25: 399-407$.

18 Petrie JC, Jeffers TA, Robb OJ, Scott AR, Webster J. Atenolol, sustainedrelease oxprenolol and long acting propranolol in hypertension. $\mathrm{Br}$ Med f 1980;281:1573-4.

19 Littler WA, Honour AJ, Pugsley DJ, Sleight P. Continuous recording of direct arterial pressure in unrestricted patients; its role in the dagnosis and management of high blood pressure. Circulation 1975;51:1101-6.

${ }^{20}$ Floras JS, Jones JV, Fox P, Hassan MO, Turner KL, Sleight P. The effect of long-term, once-daily administration of atenolol on the blood pressure of hypertensive subjects. 7 Cardiovasc Pharmacol 1981 ;3:958-64.

21 Millar-Craig MW, Mann S, Balasubramanian V, Altman D, Raftery EB. The acute and chronic effects of oxprenolol on ambulatory blood pressure and heart rate in essential hypertension. Br $\mathcal{f}$ Clin Pharmacol 1979;8: 389P.

${ }^{22}$ Mann S, Millar-Craig MW, Altman D, Melville D, Raftery EB. The effects of metoprolol on ambulatory blood pressure. Clin Sci $1979 ; 57$, suppl 5: 375-7s. 
${ }^{23}$ Mann S, Millar-Craig MW, Balasubramanian V, Raftery EB. Propranolol LA and ambulatory blood pressure. Br f Clin Pharmacol 1980;10: 443-7.

${ }^{24}$ Mehta SK, Walsh JT, Moni K, Goldberg AD. Single daily dosage of acebutalol in hypertensives; the effects on the circadian rhythms as measured with 24 hour blood pressure monitoring. In: Stott FD, Raftery EB, Goulding LG. International Symposium on Ambulatory Monitoring, 1979. London: Academic Press, 1979:197-202.

25 Littler WA, Honour AJ, Sleight P, Stott FD. Continuous recording of direct arterial pressure and electrocardiogram in unrestricted man. Br Med F 1972;iii:76-8.

26 Stott FD. The Oxford portable blood pressure transducer. In: Clement DL, ed. Blood pressure variability. Lancaster: MTP Press, 1979:55-60.

27 Sleight P, Floras JS, Jones JV. Automatic analysis of continuous intraarterial blood pressure recordings. In: Clement DL, ed. Blood pressure variability. Lancaster: MTP Press, 1979:61-6.

28 Ott L. An introduction to statistical methods and data analysis. Toronto: Duxbury Press, 1977:383.

29 Kerlinger FN. Foundations of behavioral research. New York: Holt Rinehart and Winston, 1973:269-82.

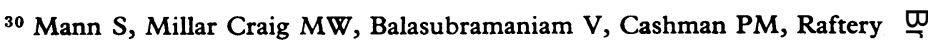
EB. Ambulant blood pressure: reproducibility and the assessment of interventions. Clin Sci 1980;59:497-500.

31 Gould BA, Mann S, Davies AB, Altman D, Raftery EB. Does placebo lower blood pressure? Lancet 1981 ;ii:1377-81.

32 Erikssen J, Nundal R, Thaulow E, Nitter-Hauge S. Dosing intervals in beta-blocking therapy. Lancet $1980 ; \mathrm{ii}: 800-1$.

${ }^{33}$ Amery A, DePlaen J-F, Lignen P, McAinsh J, Reybrouch T. Relationship between blood level of atenolol and pharmacologic effect. Clin Pharmacol Ther 1977;21:691-9.

34 Vaughan-Williams EM, Hassan MO, Floras JS, Sleight P, Jones JV. Adaptation of hypertensives to treatment with cardioselective and nonselective beta-blockers. Absence of correlation between bradycardia and blood pressure control, and reduction in the slope of the Q-T/R-R relation. Br Heart $\mathcal{f} 1980 ; 44: 473-87$.

35 Brundin T, Edhag O, Lundman T. Effects remaining after withdrawal of long-term beta-receptor blockade. Reduced heart rate and arterial haemodynamic response to acute propranolol administration. $\mathrm{Br} \mathrm{Heart} \mathcal{F}$ $1976 ; 38: 1065-72$.

(Accepted 18 August 1982)

\section{SHORT REPORTS}

\section{Decrease in pancreatic steatorrhoea by positioned-release enzyme capsules}

Oral pancreatic enzyme supplements used in treatment of pancreatic steatorrhoea are partly inactivated by acid and pepsin in the stomach. When given by mouth in a therapeutic dosage $22 \%$ of trypsin and only $8 \%$ of lipase is active at the ligament of Treitz. ${ }^{1}$ Many attempts have been made to protect oral pancreatic enzyme supplements by raising gastric $\mathrm{pH}$ with antacids, reducing gastric acid and pepsin output with $\mathrm{H}_{2}$-receptor antagonists, or by providing an enteric coating resistant to acid and pepsin, ${ }^{23}$ but few have been successful.

The optimal site for enzyme release from an enteric coated preparation is in the pyloric antrum or the proximal duodenum. A "positionedrelease" capsule (Duocap, Biorex Laboratories Ltd, London) designed to release its contents there, was developed for another drug. ${ }^{4}$ The original idea for the use of Duocaps to administer pancreatic enzymes was suggested by Professor J Kohn (Department of Biochemistry, University of Surrey). An uncontrolled study of five patients showed a significant decrease of steatorrhoea when treated with pancreatic enzymes in Duocaps compared with the preparation normally taken. The present study was designed to measure the effectiveness of delivering enzymes in Duocaps in a controlled trial.

\section{Patients, methods, and results}

In a double-blind crossover study outpatients receiving their normal diets took pancreatin BPC $320 \mathrm{mg}$ three times daily before main meals, either in a Duocap or in a gelatine capsule of identical appearance for two weeks, followed by the other formulation for a further two weeks. Allocation was randomised in groups of four. Total daily intake was lipase 19050 BP units, protease $1330 \mathrm{BP}$ units, and amylase $22860 \mathrm{BP}$ units. Other supplements were stopped and no antacids or $\mathrm{H}_{2}$-receptor antagonists were given. To synchronise enzyme release with meals Duocaps were given half an hour before, and standard capsules at the start of, the meal. Patients completed a diary noting time of taking the capsules, frequency and nature of bowel actions, symptoms, and their diet.

In the last three days of both two-week periods patients collected their stools for measurement of faecal fat. Throughout both weeks during which three-day collections were made the patients were asked to keep to exactly the same diet. Stools were weighed and stored at $-20^{\circ} \mathrm{C}$ before analysis in batches in one laboratory using Anderson's modification of the Van de Kamer $^{5}$ method.

Thirteen patients, including 10 men (mean age 50.8 years, range $16-68$ years) with steatorrhoea due to confirmed pancreatic insufficiency, were studied. Mean pre-study faecal fats were $102 \pm 15 \mathrm{mmol} / 24 \mathrm{~h}$. Five had alcoholic pancreatitis, five idiopathic chronic pancreatitis, and three had had surgery or trauma. All were clinically stable. Eight ate low fat diets, one a diabetic diet, and the remainder ate freely.

Faecal fat output while the patients were taking the two formulations is shown in the figure. The mean output with the control capsules was $194.8 \pm$ $28.1 \mathrm{mmol} / 24 \mathrm{~h}$ compared with $151 \cdot 8 \pm 30.0 \mathrm{mmol} / 24 \mathrm{~h}$ with Duocaps $(p<0.05 ; n=13)$. There was no difference between those taking Duocaps in the first study period or the second. Faecal wet weight was reduced slightly

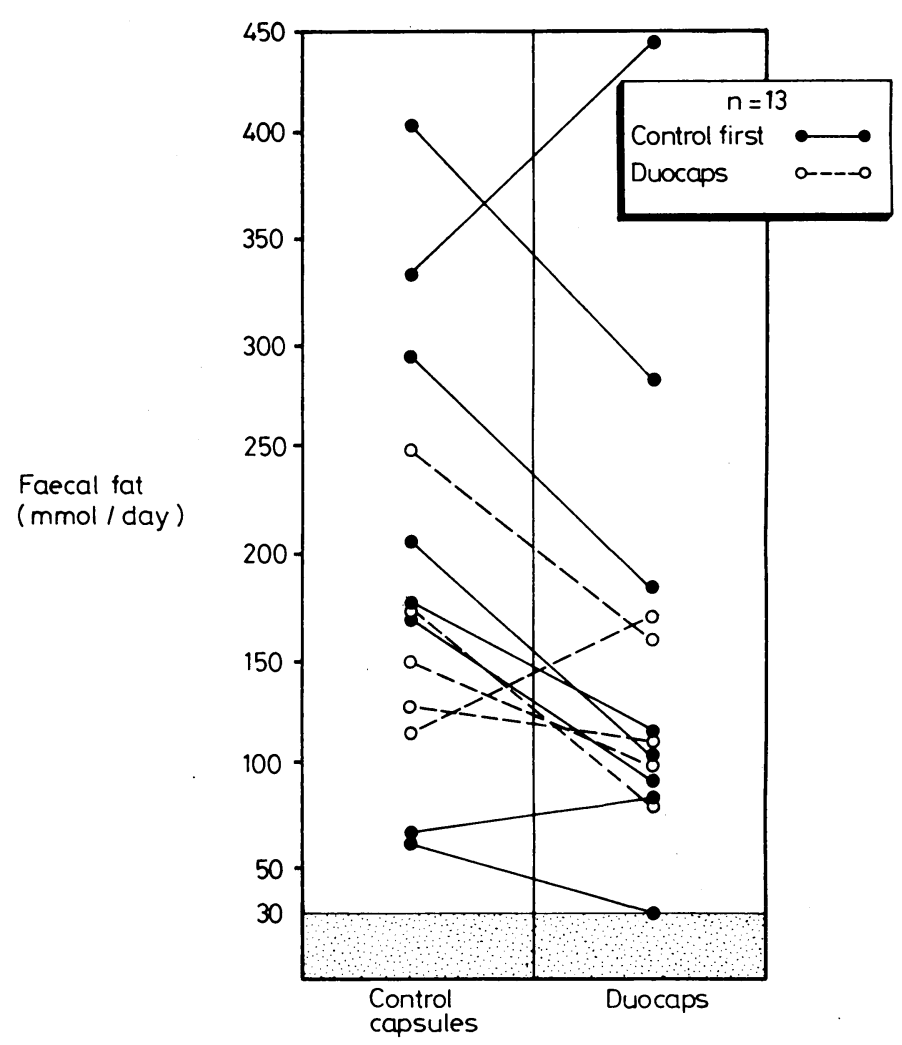

Mean daily faecal fat output for 13 patients when pancreatic enzymes were given in control capsules (left column) and Duocaps (right column) during alternate two-week periods.

with Duocaps compared with the control capsules (from $502 \pm 97$ to $486 \pm$ N $112 \mathrm{~g} / 24 \mathrm{~h}$; not significant; $\mathrm{n}=13$ ). The mean number of stools per day was $2 \cdot 8$ with control capsules and $2 \cdot 6$ with Duocaps (not significant; $n=13$ ). Mean body weight was unchanged $(63.4$ and $63.6 \mathrm{~kg}$ with control capsules and Duocaps respectively). Symptoms were minimal and the same with the two treatments. Patients' preferences were divided equally between the two formulations.

\section{Comment}

Mean daily faecal fat output was decreased by $43 \mathrm{mmol}(22 \%)$ when pancreatic replacement enzymes were taken in Duocaps compared with standard capsules. The small daily dose of lipase $(<20000 \mathrm{BP}$ 